\title{
Comercio y trabajo: utilidades subjetivas y derechos humanos en la negociación de acuerdos comerciales - los casos de Colombia y Perú*
}

JuAN JOSÉ FERNÁNDEZ DuSSO**

Artículo recibido: 1 de junio de 2017

Artículo aprobado: 1 de septiembre de 2017

Doi: http://dx.doi.org/10.12804/revistas.urosario.edu.co/desafios/a.5814

Para citar este artículo: Fernández Dusso, J. J. (2018). Comercio y trabajo: utilidades subjetivas y derechos humanos en la negociación de acuerdos comerciales - los casos de Colombia y Perú. Desafíos, 30(1), 47-89. Doi: http://dx.doi.org/10.12804/revistas.urosario.edu.co/ desafios/a.5814

\section{Resumen}

En 2004, los gobiernos de Perú y Colombia iniciaron, conjuntamente con Ecuador, la negociación de un acuerdo de libre comercio con el Gobierno de Estados Unidos. Retirado Ecuador del proceso y desligadas las negociaciones de los dos países restantes, el documento negociado entre Perú y Estados Unidos fue ratificado en 2006 y 2007 por los congresos de cada uno respectivamente. Por su parte, el negociado por Colombia vio prolongada su revisión y aprobación por parte del congreso norteamericano. ¿Qué explica las mayores dificultades para la aprobación del acuerdo entre Colombia y Estados Unidos? Para el periodo en revisión, se encuentra una mayor oposición conjunta al

* El autor agradece el apoyo de los expertos encuestados, así como los comentarios de Enrique Peruzzotti, Juan Tokatlian, Marcelo Saguier y Jorge Battaglino en una primera fase del trabajo; también los comentarios de los evaluadores anónimos de esta revista.

** Profesor del Departamento de Estudios Políticos de la Universidad Icesi, en Cali (Colombia). Correo electrónico: jjfernandez@icesi.edu.co orCID: http://orcid. org/0000-0002-8281-1709 
acuerdo colombiano que condiciona su aprobación a la solución de asuntos relacionados con derechos fundamentales de los trabajadores. Pero la divergencia se explica aqui tras un análisis de la respuesta del Gobierno colombiano a la presión trasnacional, que devela una ineficaz, estrategia del presidente Uribe condicionada por la incompatibilidad percibida entre las demandas de la oposición y su política de seguridad interna. Palabras clave: Colombia, Perú, EE.UU., derechos laborales, derechos humanos, sindicatos, TLC.

\title{
Trade and Labor: Subjective Utilities and Human Rights in Trade Agreement Negotiations - The Cases of Colombia and Peru
}

\begin{abstract}
In 2004 the Peruvian and Colombian governments began, alongside Ecuador, negotiating a trade agreement with the government of the United States of America. After Ecuador's withdrawal from the process, Peru and Colombia separated their negotiations with the United States. Peru reached an agreement with the United States that was ratified in 2006 and 2007, respectively. However, the approval of the accord with Colombia by the United States' Congress was significantly delayed. What were the forces behind this delay? This article emphasizes a strong transnational opposition to the United States-Colombia agreement that, in turn, conditioned its approval on the Colombian government's recognition and protection of workers' rights. The divergence between the Perwian and the Colombian case is explained by the Colombian government's response to such claims: one that reveals an ineffective strategy shaped by President Uribe's perceived incompatibility between those transnational demands and his national security policy.
\end{abstract}

Keywords: Colombia, Peru, labor rights, US A, buman rights, unions, free trade agreements. 


\title{
Comércio e trabalho: utilidades subjetivas e direitos humanos na negociação de acordos comerciais - os casos da Colômbia e o Peru
}

\begin{abstract}
Resumo
Em 2004 os governos do Peru e a Colômbia iniciaram, conjuntamente com o Equador, a negociação de um Acordo de Livre Comércio com o governo dos Estados Unidos. Retirado o Equador do processo e desligadas as negociações dos dois países restantes, o documento negociado entre o Peru e os Estados Unidos foi ratificado em 2006 e 2007 pelos Congressos de cada um respetivamente, mas o negociado pela Colômbia viu prolongada a sua revisão e aprovação por parte do Congresso norte-americano. Que explica as maiores dificuldades para a aprovação do acordo entre a Colômbia e os Estados Unidos? Para o periodo em revisão, encontra-se uma maior oposição conjunta ao acordo colombiano que condiciona a sua aprovação à solução de assunto relacionados com direitos fundamentais dos trabalhadores. Mas a divergência explicase aqui após uma análise da resposta do governo colombiano à pressão transnacional, que revela uma ineficaz estratégia do presidente Uribe, condicionada pela incompatibilidade percebida entre demandas da oposição e a sua politica de segurança interna. Palavras-chave: Colômbia, Peru, USA, direitos laborais, direitos bumanos, sindicatos, TLC's.
\end{abstract}

\section{Introducción}

En 2004, los gobiernos de Perú y Colombia iniciaron un proceso de negociación con el Gobierno de Estados Unidos para la definición de un acuerdo de libre comercio (TLC) ${ }^{1}$. La conclusión de las rondas de negociación y la firma de los acuerdos entre las respectivas partes se dio a inicios de 2006. Sin embargo, mientras que el TLC entre Perú y Estados Unidos fue implementado a principios de 2009, tras ratificación en 2006 y 2007 por los respectivos países; la negociación del acuerdo con Colombia continuó hasta octubre de 2011, a la espera

\footnotetext{
1 Inicialmente la negociación se dio con Perú, Colombia y Ecuador como una de las partes, y Estados Unidos como la otra. A lo largo del proceso Ecuador se retiraría, mientras que Perú y Colombia seguirían llevando la negociación de manera independiente, lo que condujo a la definición de dos acuerdos bilaterales, en vez de al multilateral inicialmente proyectado (Silva, 2007).
} 
del trámite y la aprobación en el congreso norteamericano. En esto, la presión ejercida por actores opositores locales peruanos y colombianos desde la arena doméstica estadounidense, reconocible dentro del marco de dinámicas de redes sociales trasnacionales (Keck \& Sikkink, 1998) es un factor importante que remite a trabajos como el de Anner y Evans (2004), quienes señalan que el crecimiento de una red cada vez más compleja de relaciones trasnacionales entre grupos sindicales y algunas ONG ha manifestado su capacidad de acción a través de presiones de distinto tipo, trabajando directamente contra los efectos nocivos de los TLC sobre los trabajadores.

En una exploración del NAFTA (por sus siglas en inglés: North American Free Trade Agreement), Frundt (1998; 2002) indica cómo iniciativas de organizaciones no gubernamentales y sindicales estadounidenses han estimulado respuestas del sindicalismo latinoamericano para demandar mayores niveles de protección laboral. En este camino, el autor destaca como elemento fundamental la utilización de las herramientas ofrecidas por el us General System of Preferences $(\mathrm{GSP})^{2}$. Asimismo, reconoce cómo las cláusulas sociales vinculantes, de común uso en Europa y el Mercosur, y la inclusión de protocolos modificatorios con cláusulas sobre derechos ambientales, humanos y laborales en acuerdos comerciales han sido mecanismos recurrentes.

En lo que a los trabajadores colombianos y peruanos respecta, los mecanismos del GSP han sido una herramienta importante; particularmente para los procesos de ratificación de los TLC aquí estudiados, los protocolos fueron la herramienta de ajuste fundamental.

Las modificaciones, sin embargo, no llevaron a ratificaciones simultáneas en ambos casos, lo que lleva a explorar, más allá de las estructuras

\footnotetext{
2 Los mecanismos establecidos por el GSP han sido de utilidad para los intereses de los trabajadores en países con acceso comercial preferencial al mercado estadounidense o de países que aspiren a él, en tanto que la reducción de tarifas arancelarias está ligada al cumplimiento de derechos laborales fundamentales por parte de los países a los que se les otorgó el privilegio. Bajo estos instrumentos, el mantenimiento de las tarifas depende del control y monitoreo estadounidense, que puede ser solicitado por cualquiera de los interesados.
} 
de presión en las que redes trasnacionales operan, la singularidad en la respuesta de cada Gobierno.

Debido a la escasez de estudios sobre este problema ${ }^{3}$, este trabajo reconstruye los procesos de ratificación de los acuerdos comerciales entre Perú y Estados Unidos, y Colombia y Estados Unidos tras los momentos de negociación y firma de los textos entre las partes. El objetivo fundamental, además de dar cuenta de la presión de redes trasnacionales, es identificar las variables causales de la divergencia. Para el periodo en revisión, se encuentra una mayor oposición conjunta al acuerdo colombiano que condiciona su aprobación a la solución de asuntos relacionados con derechos fundamentales de los trabajadores. Pero la divergencia se explica aquí tras un análisis de la respuesta del Gobierno colombiano a la presión trasnacional, que devela una ineficaz estrategia del presidente Uribe, condicionada por la incompatibilidad percibida entre las demandas de la oposición y su política de seguridad interna.

Las negociaciones de Perú y Colombia fueron seleccionadas por las similitudes entre los países en lo respectivo a condiciones estructurales -macroeconómicas, sociales, geopolíticas, productivas y estatalesal desarrollo paralelo de las respectivas negociaciones y a la divergencia en los procesos de aprobación de sus acuerdos. La ausencia de estudios sobre el periodo de ratificación, así como el acento puesto por algunos trabajos en las presiones trasnacionales o en el proceso de negociación formal, reclaman un ejercicio de este tipo. Mientras que la conjugación de ambas dimensiones dará una comprensión más completa de ambos casos, que evidencia bondades y límitaciones de las distintas perspectivas de análisis, la comparación final de ambas

\footnotetext{
3 Existen abundantes estudios sobre aspectos jurídicos, implicancias comerciales, políticas, económicas o sociales de los acuerdos, así como sobre actores de interés y sus demandas (Rettberg et al., 2014). Existen, sin embargo, tan solo algunas publicaciones sobre los procesos de negociación. Solo unas pocas llegan a recoger diversas dimensiones del proceso mismo de negociación (o dan cuenta de la presión trasnacional, o de la negociación en particular), y generalmente se dan para el caso colombiano (Silva, 2007; de la Cadena, 2008; Garay et al., 2011; Rettberg et al., 2014). No hay en cambio trabajos sobre el proceso de ratificación para los casos ni interacción explorada sobre las distintas dimensiones.
} 
experiencias, a través del modelo de negociación internacional que aquí se propone, servirá para recordar la pertinencia de construir teorizaciones que superen el supuesto de racionalidad maximizadora del actor, común en las apuestas teóricas del campo. El paradójico dilema afrontado por Uribe Vélez (del que resultará la divergencia entre cada ratificación), será la clave para presentar importantes limitaciones en este sentido.

Este trabajo se abre con una revisión general de trabajos sobre economía política y negociación internacional, y el establecimiento de un marco teórico para el desarrollo posterior. Inmediatamente se inicia la exploración de los casos, realizando una primera descripción de los procesos de negociación y, enmarcada dentro de la literatura sobre redes sociales trasnacionales, se establece el contexto de acción en el cual los agentes negociadores debieron operar. Una vez hecho esto, se recurre al modelo de análisis propuesto por Cameron y Tomlin (2000) para profundizar sobre los elementos estructurales y estratégicos en cada uno de los procesos de ratificación.

\section{Negociaciones internacionales: explicaciones alternativas}

Cameron y Tomlin (2000) realizan una exploración de cuatro posibles aproximaciones teóricas para abordar el proceso de negociación del NAFTA: i) la del neorrealismo para la cual hacen una revisión del trabajo de Krasner (1990); ii) la del neoliberalismo institucional para la que reconocen como autor central en la discusión entre esta aproximación y la anterior a Keohane (1990); iii) la de la teoría de juegos de doble nivel para la cual hacen una revisión de la propuesta de Putnam (1993) y siguen con el análisis de proposiciones de Evans y Moravcsik (1993), y iv) la de la negociación internacional, apoyándose en el Threshold-Adjustment Model de Druckman (1986), así como en literatura complementaria sobre acción racional y teorías prospectivas desarrollada por diversos autores (Lax \& Sebenius, 1986; Lax, Sebenius et al., 1985, para mencionar algunos). 
El argumento central del neorrealismo, señalan los autores, enfoca el problema desde una perspectiva estructuralista que afirma que "la cooperación formal y la creación de nuevas instituciones son tareas muy difíciles cuando existen asimetrías de poder entre dos Estados" (Krasner, 1990). Resaltan del trabajo de Krasner (1990) seis proposiciones teóricas con las que el autor desestima la posibilidad de que acuerdos comerciales bilaterales se presenten (pp. 48-50) —en particular refiriéndose a la potencial negociación entre Estados Unidos y México en el marco del proceso de creación del NAFTA— y recurren al neoliberalismo institucional de Keohane (1990) para refutar su proposición. La respuesta de Keohane (1990) a Krasner (1990) ofrece el siguiente argumento: las asimetrías tendrán diferente efecto sobre las dos partes dependiendo de factores como el nivel de poder de cada Estado según sus recursos disponibles para la negociación y el nivel de interdependencia entre estos Estados o el nivel de fragmentación institucional de cada uno de ellos, lo que abrirá espacios para la obtención de resultados favorables para ambas partes en puntos específicos de la negociación. Así, afirma Keohane (1990), la posibilidad de acuerdos comerciales bilaterales existe.

Un mayor desarrollo teórico para refutar la posición de Krasner (1990) es innecesario: las experiencias del NAFTA y de los casos aquí abordados bastan para hacerlo. La mención, sin embargo, es útil para destacar la discusión sobre asimetrías de poder y negociaciones de acuerdos internacionales. La perspectiva del neoliberalismo institucional, con Keohane (1990) a la cabeza, podría ser útil para el análisis de los casos ya que reconoce la necesidad de involucrar aspectos institucionales - limitaciones, intensidad de preferencias y nivel de fragmentación estatales — dentro de la explicación, dejando atrás la imposibilidad que la perspectiva neorrealista impone. No obstante, como es ya sabido, el neoliberalismo institucional es débil como herramienta teórica para explicar la forma en que la agencia, inscrita dentro de condicionamientos estructurales particulares, tiene incidencia sobre los resultados obtenidos. Sus problemas: reconoce el escenario internacional, pero desconoce los escenarios domésticos; asume preferencias de cada Estado como fijas, y desconoce el papel 
que actores diferentes al Estado (redes, por ejemplo), juegan en la arena internacional (Cameron \& Tomlin, 2000, pp. 30-31).

Entra aquí entonces la perspectiva de juegos de doble nivel. En ella Putnam (1993) establece una diferencia entre el nivel 1 de negociación, que se da entre los agentes negociadores de los dos distintos países, y el nivel 2 de negociación determinado por discusiones presentes entre agentes domésticos sobre el acuerdo. Esta perspectiva define para su modelo al win-set del nivel 2 de negociación como la estructuración de cualquier acuerdo posible en el nivel 1 de negociación que pudiera ganar una votación de aprobación. La posibilidad de un acuerdo en el nivel 1 de negociación estará determinada por la condición que los dos win-sets del nivel 2 de negociación encuentren, es decir que converjan y constituyan una coalición suficiente. Las etapas de ratificación, señala el autor, se constituyen en el vínculo esencial entre las dimensiones local e internacional.

Aquí las tres principales hipótesis de Putnam (1993) sobre el tamaño requerido de los win-sets del nivel 2 que seguirá este trabajo: i) el tamaño del win-set depende de la distribución de poder, preferencias y posibles coaliciones entre elementos del nivel 2 de negociación ${ }^{4}$; ii) el tamaño del win-set depende de las instituciones políticas del nivel 2 de negociación ${ }^{5}$, y iii) el tamaño del win-set depende de las estrategias de los agentes negociadores del nivel 1 de negociación ${ }^{6}$.

La construcción de Putnam (1993) es útil para reconocer las estructuras de negociación de las dos distintas arenas y su interacción. Y, como fuese mencionado, serán importantes para este ejercicio. Pero cuenta con una debilidad presente específicamente en lo referente a

\footnotetext{
4 A menor el costo de no acuerdo para estos, menor el win-set.

5 A mayor poder del Estado en términos de autonomía frente a presiones domésticas, más débil su posición relativa de negociación en la arena internacional —el ejemplo de Putnam (1993): diplomáticos representando una dictadura serán menos capaces que representantes de una democracia de reclamar credibilidad por sobre presiones domésticas que esgriman condiciones desfavorables resultantes del acuerdo-.

6 Voluntad de ambas partes de llevar a aprobación el acuerdo, diferencias sobre aspectos particulares de este y estrategias derivadas de ello.
} 
su tercera hipótesis, ya que al igual que los modelos de redes trasnacionales no ofrece herramientas suficientes para explicar en detalle la dinámica y las lógicas propias de los agentes negociadores del nivel 1 de negociación. Es aquí que asimilados los factores institucionales del neoliberalismo institucional y los juegos de doble nivel trabajados por Putnam (1993) llegamos a la propuesta de Cameron y Tomlin (2000).

En la propuesta se señala cómo la negociación consta de complejos patrones, en los que las respuestas de cada parte están determinadas por la utilidad subjetiva que tengan sobre las alternativas del no acuerdo en distintos momentos de la negociación. Sobre esto, los autores afirman que la utilidad subjetiva asignada a las alternativas del no acuerdo es lo que determinará la orientación al riesgo de los agentes, y que esta orientación será la que determine los patrones de respuesta de cada parte durante su interacción. Los elementos clave en la construcción de utilidades subjetivas se encuentran, afirman los autores, en el marco institucional en el que las partes operen.

Apoyados en Putnam (1993), e integrando los supuestos teóricos desarrollados sobre el proceso de negociación a su tercera hipótesis, los autores argumentan que negociadores internacionales de Estados poderosos tenderán a atender menos a las demandas de los Estados débiles que a las de sus actores domésticos, mientras que negociadores de Estados débiles tenderán a atender más a las demandas de los Estados poderosos que a las de sus actores domésticos. Sobre esta afirmación desarrollan además un corolario: negociadores internacionales en Estados débiles podrán usar con mayor credibilidad su vulnerabilidad frente a presiones internacionales para justificar la imposición de reformas domésticas desventajosas.

Finalmente, desarrollan las siguientes proposiciones:

A menor utilidad subjetiva que una parte de la negociación asigne a la alternativa de no acuerdo: (i) más percibirá al acuerdo en negociación en términos de las ganancias que este ofrezca sobre la alternativa del no acuerdo; (ii) más adversa al riesgo será frente a la opción de alcanzar esas ganancias; (iii) menos dispuesta 
estará a poner en riesgo al acuerdo al retener concesiones; (iv) más concesiones ofrecerá en el proceso de ajuste en orden de obtener el acuerdo. Y viceversa (Cameron \& Tomlin, 2000, p. 29).

Este trabajo se centrará en esta apuesta para explicar los resultados divergentes en los tiempos de ratificación de los acuerdos. Lo hará a partir de la identificación de estructuras de negociación, su interacción y las utilidades subjetivas que las partes del acuerdo le otorguen a este ${ }^{7}$. Sin embargo, y como fuera indicado, la literatura sobre redes trasnacionales será central en la reconstrucción del contexto en el cual los negociadores debieron operar. Sus marcos de análisis ofrecen mejores herramientas que los modelos de doble nivel, por ejemplo, para la reconstrucción de este espacio en particular.

\section{Aplicación del marco a los casos}

\section{Los casos: el proceso, los actores y los temas álgidos de negociación}

En 2004 los gobiernos de Perú y Colombia iniciaron paralelos procesos de negociación con el Gobierno de Estados Unidos para la definición de un TLC. El gobierno colombiano del entonces presidente Álvaro Uribe destacó la importancia de adelantar un acuerdo con Estados Unidos dentro del marco de una estrategia que pretendía la profundización de relaciones comerciales internacionales y la búsqueda específica de acceso preferencial, bajo esquemas bilaterales, a mercados de Estados Unidos y la Unión Europea ${ }^{8}$. Los gobiernos peruanos de Alejandro Toledo y Alan García ${ }^{9}$ por su parte destacaron

\footnotetext{
7 Es preciso anotar que el modelo fue diseñado para la exploración de negociaciones entre equipos negociadores. La aplicación del mismo a momentos de ratificación, si bien útil, obliga a considerar una mayor complejidad en la constante configuración de utilidades subjetivas de los sujetos revisados: es aquí cuando se hace más sensible el vínculo entre las distintas arenas de negociaciones.

8 Ver: www.tlc.gov.co

9 La posición de García como candidato a la presidencia fue otra. Su posición al asumir el cargo fue girando a favor del acuerdo (Cameron, 2011).
} 
la importancia que como potenciador del crecimiento para un mercado interno reducido y de bajo poder adquisitivo representaba la consolidación del ingreso comercial preferencial a la mayor economía - y más grande importadora- del mundo ${ }^{10}$.

Junto con Chile, estos dos países latinoamericanos se destacan por ser los más activos del subcontinente en la búsqueda, negociación y promoción de acuerdos comerciales bilaterales ${ }^{11}$. Las negociaciones de ambos con Estados Unidos, no obstante, generaron intensas discusiones en ambas arenas con respecto a la viabilidad, relevancia e impacto de tales acuerdos.

Los temas centrales de controversia, en los tres países negociantes, giraron en torno a: i) propiedad intelectual; ii) agricultura; iii) medio ambiente; iv) inversión extranjera, y v) derechos laborales.

En materia de propiedad intelectual existen dos casos sobre los que se reconoce el mayor debate: la apropiación y explotación de recursos naturales de uso tradicional de antiguas culturas nativas, y el problema de acceso a medicamentos por cuenta de la expansión de patentes y sus consecuentes precios altos (Rodríguez \& Rodríguez, 2007) ${ }^{12}$. En materia agrícola, el debate central giró en torno a las graves implicancias de una apertura unilateral de mercados, en tanto Estados Unidos mantendría su poderosa política de subsidios al agro nacional, que intensificaría las asimetrías que afectan el futuro de la producción en

10 Ver: www.tlcperu-eeuu.gob.pe Tanto Colombia como Perú han gozado de acceso comercial preferencial al mercado estadounidense desde la promulgación del ATPA en 1991 (Ley de Preferencias Arancelarias Andinas; componente comercial del programa andino Guerra contra las Drogas promulgado por el presidente G. Bush en diciembre de 1991, con alcance para Colombia, Bolivia, Ecuador y Perú), posteriormente ATPDEA, pero su vencimiento programado para el año 2006 se constituyó en un incentivo mayor para el aceleramiento y la ratificación de los acuerdos en ambos países. Extensiones fueron ofrecidas para Perú hasta la aprobación de su acuerdo, y para Colombia hasta el primer semestre de 2011.

11 Además de sendos acuerdos comerciales con países latinoamericanos, ambos se han visto inmersos en la promoción de negociaciones de acuerdos comerciales con, entre otros y además de Estados Unidos, Canadá, la Unión Europea, China, Corea y AELC.

12 Ver además los estudios conjuntos de IFarma y la Ops en www.ifarma.org 
los países latinoamericanos y generan transformaciones socioeconómicas nocivas (Garay, Barbieri \& Espinoza, 2004).

En materia de medio ambiente los puntos más importantes giraron alrededor del asunto de legislación y soberanía, que incluye regulación y mecanismos de cooperación sobre la inversión en explotación de recursos naturales, entre otros. En materia de inversión extranjera, los puntos álgidos se refirieron a la negociación de cláusulas de apropiación y menoscabo que conceden privilegios a la inversión extranjera que afectan la competitividad de la inversión nacional, así como la capacidad del Estado para ejercer tareas autónomamente en materia de políticas públicas (Public Citizens Global Trade Watch, 2005; Rodríguez \& Rodríguez, 2007). Finalmente, en lo referente a derechos laborales, los temas centrales del debate giraron en torno a la aplicación y al cumplimiento de estándares laborales de reconocimiento internacional.

Estas líneas, como se menciona en Pizarro (2006), dan cuenta de nuevos intereses políticos puestos sobre la mesa a través de este tipo de acuerdos, que empiezan a dar luces para entender la complejidad de coaliciones que toman forma durante el proceso: coaliciones mixtas, siguiendo los términos de Hiscox (2001), antes que las sectoriales o de clase predominantes que el mismo Hiscox $(2001 ; 2008)$ esperaría. Para ambos casos se encontró cómo farmacéuticas nacionales, la iglesia católica, algunas ONG y sindicatos, por ejemplo, operaron paralela o conjuntamente en contra del acuerdo mismo o de algunos de sus aspectos.

El texto negociado entre Colombia y Estados Unidos fue firmado en febrero de 2006 por las partes. El texto negociado entre Perú y Estados Unidos fue firmado en abril de ese mismo año. Sin embargo, los documentos serían firmados ante la expresa inconformidad de la bancada demócrata del congreso estadounidense. Faltaba aún la aprobación de los respectivos documentos en congresos y cortes nacionales.

Presiones provenientes de actores de interés colombianos, peruanos y estadounidenses fueron institucionalizadas a través del congreso norteamericano. La estrecha relación entre el sindicalismo norteamericano y congresistas del partido demócrata permitió una presión 
política poderosa por vías institucionales en el ámbito local estadounidense (Center for Responsive Pilitics, 2017). La nueva distribución de sillas en dicho congreso, con mayorías demócratas en ambas cámaras desde 2007, así como la obtención por parte de algunos demócratas de las presidencias de la Cámara de Representantes y de la Comisión de Vías y Arbitrios de esa misma cámara (Ways and Means Committee) ${ }^{13}$, fue suficiente para que los azúles condicionaran la aprobación de ambos textos.

Para su ratificación, los gobiernos negociadores debieron aceptar modificaciones sustantivas incorporadas durante el primer semestre de 2007. Las modificaciones tocaron varios de los temas neurálgicos del debate: se cambió lo negociado en relación con asuntos ambientales, propiedad intelectual, contratación pública y derecho laboral ${ }^{14}$.

En materia ambiental, por ejemplo, se introdujeron cláusulas referentes al cumplimiento de convenios y protocolos internacionales de salvaguarda - cumplir con la Convención sobre Comercio de Especies en Riesgo de Extinción o el Protocolo de Montreal sobre sustancias nocivas para la capa de ozono-y la definición de posiciones con respecto a problemas de dumping ambiental. En cuanto a propiedad intelectual, específicamente en lo referente a medicamentos, se estipuló la protección de datos de prueba, la no ampliación del plazo de las patentes por demoras en el registro, y la eliminación de la exigencia posterior sobre la autoridad sanitaria como vigilante paralela de asuntos sanitarios y patentes, entre otros.

Finalmente, en materia laboral, los protocolos modificatorios reafirmaron las obligaciones de los Estados con la OIT, que obligaron a la aceptación y aplicación de los principios fundamentales consignados por su declaración sobre Principios Fundamentales del Trabajo, y exigieron el respeto de los estándares internacionales establecidos.

\footnotetext{
13 Es el presidente de esta comisión quien programa la presentación del proyecto para aprobación en el congreso.

14 Ver textos oficiales y protocolos modificatorios en www.tlc.gov.co y www.tlcperu-eeuu. gob.pe
} 
Lo ocurrido se condice con la proposición de Cameron y Tomlin (2000) según la cual negociadores internacionales de Estados poderosos tenderán a atender más a las demandas de sus actores domésticos, mientras que negociadores de Estados débiles tenderán a atender más a las de los Estados poderosos. Su corolario al respecto en estos casos, sin embargo, falla: las exigencias de congresistas demócratas estadounidenses irían en favor de reformas ventajosas para los países latinoamericanos. Una primera evidencia sobre la presencia de redes trasnacionales que ejercían presión desde la arena política estadounidense.

Anner (2004) indica cómo los primeros pasos en la conformación de alianzas trasnacionales en contra de este modelo de apertura internacional se dieron en 2001 con la declaración en contra de los TLC por parte de la ORIT (Organización Regional Interamericana de Trabajadores) ${ }^{15}$. En su declaración se propugnó la construcción de una versión distinta de los procesos de globalización, en los que el respeto a la soberanía de las naciones vinculadas y el respeto a los derechos básicos de todos los trabajadores fueran piezas fundamentales. El documento encontró correspondencia y complementación ideológica entre agrupaciones sindicales y ONG que enfrentaban la imposición de consecutivas negociaciones de acuerdos bilaterales en el continente. Este fue un primer paso para la consolidación de nuevas alianzas frente al modelo liberalizador impulsado ${ }^{16}$.

The American Center for International Labor Solidarity, conocido como el Centro de Solidaridad ${ }^{17}$, ha sido una de las organizaciones que

\footnotetext{
15 No obstante, los países con alianzas activas que se destacan son Brasil, Canadá, Perú y Estados Unidos.

16 Que, sin embargo, tuvieron que superar tensiones propias de intereses económicos e ideológicos divergentes. Sobre estos asuntos: objetivos, consensos, contradicciones y motivaciones -instrumentales, ideológicas, éticas — en la configuración de alianzas norte-sur, ONG y sindicatos, y las dificultades de estos procesos, ver, entre otros, a Tarrow (1998), Keck y Sikkink (1998), Anner (2002), Frundt (2002), Anner y Evans (2004), Compa (2004), y Anner (2008).

17 Esta organización cuenta con recursos financieros que superan los Us $\$ 20000000$ anuales. Tiene presencia directa y permanente en más de 28 países del continente y cuenta con personal especializado en asuntos relativos a derechos laborales y comercio internacional. Su ejercicio ha sido clave en la vigilancia y control de aspectos sobre violación de derechos laborales y humanos en varias de las economías de la región (Anner \& Evans, 2004).
} 
han seguido con atención asuntos sobre derechos laborales y comercio internacional. Su junta está compuesta mayoritariamente por la alta dirección de AFL-CIO (American Federation of Labor - Congress of Industrial Organizations), la mayor central obrera de Norteamérica, creada en 1955 por la fusión de AFL (1886) y CIO (1935) e integrada por 55 confederaciones nacionales e internacionales de sindicatos de Canadá y Estados Unidos. Representa más de 12 millones de trabajadores y es miembro de la Confederación Internacional de Organizaciones Sindicales Libres. Reconocida como uno de los donantes de mayor peso para el partido demócrata estadounidense (Center for Responsive Politics, s.f.), la AFL-CIO jugó un papel fundamental a lo largo de los procesos de negociación y ratificación de los acuerdos en estudio, consolidándose como el actor de presión más poderoso en lo referente a asuntos laborales a favor de los trabajadores latinoamericanos.

Así como la ORIT, el Centro de Solidaridad y la AFL-CIO, diversas organizaciones norteamericanas, colombianas, peruanas e internacionales tuvieron un papel importante en los procesos de negociación y ratificación de estos acuerdos. Su presencia fue fundamental para ejercer presión desde la arena estadounidense sobre los asuntos referidos a inversión extranjera, propiedad intelectual, medio ambiente, legislación laboral y derechos humanos ${ }^{18}$.

Los resultados se reflejaron en la aprobación de los mencionados protocolos modificatorios. Las modificaciones impuestas a los documentos fueron similares en ambos casos. Para el segundo semestre de 2007 los documentos negociados contaban con su respectivo protocolo modificatorio sancionado.

Sin embargo, mientras que el TLC entre Perú y Estados Unidos fue ratificado por el congreso norteamericano al cierre de 2007, e implementado a inicios de 2009, para el segundo semestre de 2011 el acuerdo negociado por Colombia esperaba aún trámite y aprobación en el congreso norteamericano. La aprobación de los protocolos modificatorios

18 Ver, entre otros, bilaterals.org 
no fue percibida como una solución satisfactoria a las reclamaciones expresas de algunos grupos de presión. Fueron en especial presiones en torno a la salvaguarda de derechos laborales las que se mantuvieron tras la aprobación de las modificaciones (Gassek, 2008).

La evidencia recolectada permite reconocer a los actores de presión más relevantes en esta línea, por cada país:

- Colombia: el partido Polo Democrático, la Central Única de Trabajadores (CUT), la Confederación General de Trabajadores de Colombia (CGT), la Confederación de Trabajadores Colombianos (CTC), la Confederación de Pensionados de Colombia (CPC), la Red Colombiana de Acción Contra el Libre Comercio y el ALCA (RECALCA).

- Perú: partidos Socialista y Nacionalista Peruano, la Confederación Nacional de Trabajadores del Perú (CGTP), la Central Unitaria de Trabajadores del Perú (CNT), la Confederación de Trabajadores del Perú (CTP).

- Estados Unidos: el partido Demócrata, AFL-CIO, Change to Win ${ }^{19}$, Public Citizen ${ }^{20}$.

La acción de estas organizaciones sigue las dinámicas del patrón bumerán presentando por Keck y Sikkink (1998), que se presenta en el gráfico 1.

Siguiendo su trabajo: ante procesos de negociación internacional, cuando un Estado $A$ bloquea $^{21}$ la comunicación con organizaciones civiles puede activarse una red trasnacional con miembros de los países A y B para ejercer presión sobre el Estado B —e incluso sobre

\footnotetext{
19 Change to Win es una confederación de trabajadores norteamericanos constituida en 2005 tras la separación de sus miembros de AFL-CIO. Fue constituida como alternativa a las directrices predominantes en AFL-CIO. De menor cantidad de afiliados y capacidad de lobby, desde 2009 algunos de sus miembros han ido retornando a AFL-CIO. Para entonces la posibilidad de una reunificación definitiva estaba ya en el aire (Maher, 2009; Greenhouse, 2009).

20 Ver: http://www.citizen.org/Page.aspx?pid=1328

21 Considerándose el caso de un Estado represor, aunque también el de uno inaccesible o sordo ante demandas específicas (Keck \& Sikkink, 1998, p. 13).
} 
una tercera organización_- La respuesta del Estado B será la de presión (directa o indirecta) en la arena internacional sobre el Estado $A$.

\section{Gráfico 1. El patrón bumerán}

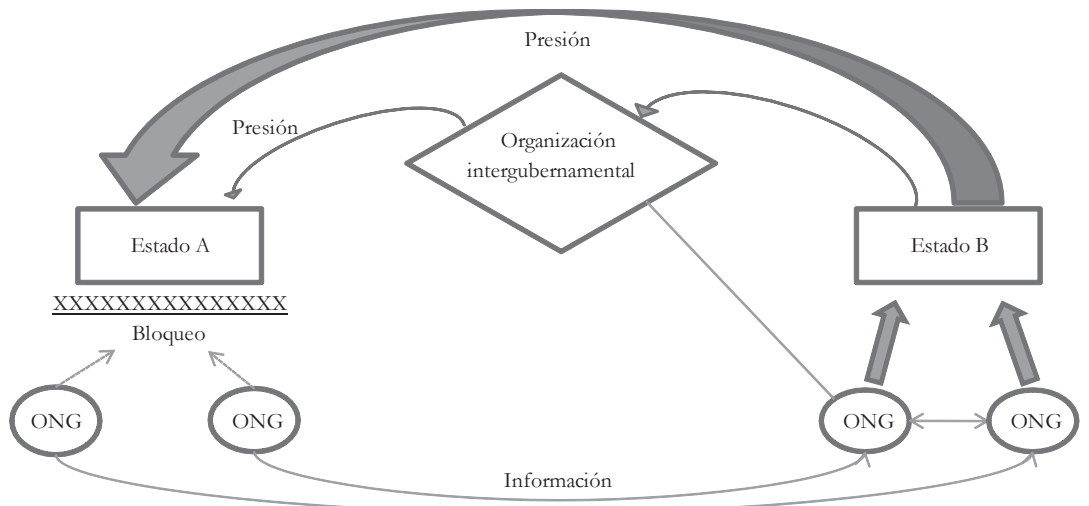

Fuente: Keck, \& Sikkink (1998).

Durante las negociaciones, organizaciones civiles de derechos humanos y laborales activaron dichas redes para ejercer presión sobre los respectivos gobiernos. Una estructura de oportunidad política (Tarrow, 1998) se vería constituida ${ }^{22}$ y reforzada por la estrecha relación entre el sindicalismo norteamericano y el partido demócrata, y la posterior distribución de sillas en el congreso norteamericano con mayorías demócratas sumando la obtención, además, de presidencias clave por parte de estos a partir de 2007. Cada una de las estrategias utilizadas por estos actores de presión se reconoció dentro del marco de tipologías señalado por Keck y Sikkink (1998): uso fundamentalmente de políticas de apalancamiento o lobby en la arena política estadounidense y desde ella hacia el Gobierno colombiano, así como de políticas de información, simbólicas y de responsabilidad o rendición de cuentas (pp. 16-25).

\footnotetext{
22 Retomando la proposición de Cameron y Tomlin (2000): negociadores internacionales de Estados poderosos tenderán a atender menos las demandas de los Estados débiles que las de sus actores domésticos, mientras que negociadores de Estados débiles tenderán a atender más las demandas de los Estados poderosos que las de sus actores domésticos.
} 
Este trabajo recoge evidencia para cada uno de los agentes de presión norteamericanos citados sobre su expreso compromiso y ejercicio dirigido a imponer sus intereses sobre la salvaguarda de los derechos fundamentales estipulados por la OIT para los trabajadores sudamericanos. En muchos casos, los comunicados oficiales emitidos por estos actores evidencian el uso de información producida por actores de presión colombianos y peruanos (AFL-CIO, 2008). Existe también evidencia para cada uno de los citados agentes de presión de las arenas peruana y colombiana sobre un ejercicio de lobby realizado directamente en la arena política estadounidense a través de comunicaciones y encuentros con representantes del congreso ${ }^{23}$. La evidencia muestra, sin embargo, una mayor presencia de ejercicios conjuntos entre actores de presión de las arenas locales norteamericana y colombiana, particularmente entre AFL-CIO y los gremios de trabajadores colombianos enumerados.

Tal diferencia puede explicarse acudiendo a Murillo y Schrank (2005), quienes al preguntarse por el paradójico proceso de crecimiento en legislación laboral latinoamericana durante los noventa, indican cómo los legados institucionales determinan posibles estrategias para garantizar la protección: en países de tradición populista y presencia significativa de partidos de base obrera, predominaran alianzas domésticas entre partidos de base popular y el sindicalismo local24; en países de fuerte tradición represiva, la alianzas trasnacionales entre organizaciones sindicales y no gubernamentales ${ }^{25}$.

Colombia es sin duda un caso de pasmosa tradición represiva. Webber (2007) explica por qué es este uno de los rasgos que más dificultades presenta para la actividad de organizaciones sociales en función de

\footnotetext{
23 Ver como ejemplo la Carta a representantes demócratas en el Congreso norteamericano, firmada por representantes de la CUT y la CGT de Perú, en agosto de 2007: http://www. citizen.org/documents/PeruvianLaborLetter-082007.pdf

24 Un ejemplo de esto es Argentina. La literatura fundamental en la que se basan para tal afirmación es la propia, además de aquella de Levitsky y Way (1998) y de Burguess y Levitsky (2003), entre otros.

25 Un ejemplo de esto es República Dominicana. La literatura fundamental en la que se basan para tal afirmación es la de Anner (2002), además de aquella de Elliott (1998) y de Frundt (1998), entre otros.
} 
objetivos de justicia social: pobre tradición sindical, legislación laboral flexible y reformas en esa línea en las últimas décadas (Cárdenas, 2006), políticas de orden represivo cobijadas hasta los noventa por la excepcionalidad del Estado de Sitio (Leal Buitrago, 2006), y nexos de actores políticos estatales y Fuerzas Armadas con grupos paramilitares de extrema derecha, que promovieron e impulsaron acciones violentas en contra de sindicalistas, organizaciones estudiantiles y militantes de izquierda (Haugaard, 2008) son los elementos más representativos. Lo cierto es que, en línea con Murillo y Schrank (2005), las condiciones para la utilización de una estrategia de presión por el respeto a derechos fundamentales, a través de redes sociales trasnacionales y ante negociaciones de un TLC con Estados Unidos estuvieron dadas.

No obstante, las estrategias trasnacionales o alianzas domésticas son caminos compatibles que, en casos como el peruano, pueden implementarse simultáneamente. Esta afirmación concuerda con el reconocimiento que hacen Schrank y Murillo (2005) de los efectos que la reforma neoliberal tenga sobre el sector laboral organizado, a pesar del crecimiento en legislación colectiva laboral favorable en ciertos casos: la liberalización y apertura ejercen presión sobre costos de mano de obra; la reforma produce amplios procesos de despido de la misma (inclusive organizada) y consecuentemente reducción del peso relativo de los sindicatos dentro de la economía y la arena política nacional Cook (2007), que conduce a la aparición de sectores informales cada vez más grandes (Levitsky \& Burguess, 2003; Roberts, 2002) Perú, de tradición distinta a la colombiana, es un caso que se ajustaría a estos cambios (Cook, 2007), dando paso a la posibilidad de que, ante negociaciones de acuerdos comerciales, estrategias simultáneas (locales y -con menor intensidad entonces- trasnacionales) puedan ser utilizadas..

Queda por ver qué se logra. La proposición de Cameron y Tomlin (2000) servirá para explicar la imposibilidad en Colombia de una respuesta satisfactoria. 
Tabla 1. Violaciones de derechos sindicales en Colombia y Perú

\begin{tabular}{|c|c|c|}
\hline & Colombia & Perú \\
\hline \multirow{8}{*}{2005} & 70 sindicalistas asesinados & 44 despidos \\
\hline & 260 amenazados de muerte & $\begin{array}{l}20 \text { transferidos de su trabajo a } \\
\text { labores no idóneas }\end{array}$ \\
\hline & 56 detenidos arbitrariamente & 29 hostigados \\
\hline & 7 víctimas de atentados & \\
\hline & 32 acosados & \\
\hline & 8 desplazados & \\
\hline & 3 desaparecidos & \\
\hline & 1 con allanamiento de hogar & \\
\hline \multirow[t]{2}{*}{2006} & 78 sindicalistas asesinados & $\begin{array}{l}2 \text { desaparecidos en una } \\
\text { manifestación }\end{array}$ \\
\hline & & 28 detenidos en una manifestación \\
\hline \multirow[b]{2}{*}{2007} & 39 sindicalistas asesinados & 45 despidos \\
\hline & 2 detenidos arbitrariamente & $\begin{array}{l}3 \text { muertos y } 9 \text { heridos en la } \\
\text { represión de una manifestación }\end{array}$ \\
\hline
\end{tabular}

Fuente: CIOSL, Informe Anual sobre las violaciones de los derechos sindicales (2006-2008)

El juego político en dos niveles: estructuras e interacción en la negociación

\section{Gráfico 2. Los niveles 1 y 2 de negociación: estructura e interacción}

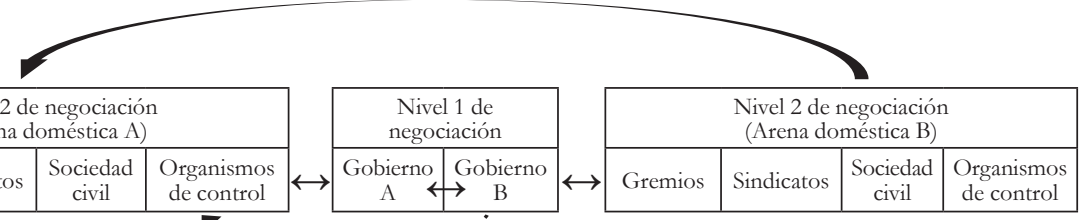

\begin{tabular}{|c|c|c|c|c|c|c|c|c|}
\hline \multicolumn{3}{|c|}{$\begin{array}{c}\text { Nivel 2 de negociación } \\
\text { (Arena doméstica A) }\end{array}$} & \multicolumn{4}{|c|}{$\begin{array}{c}\text { Nivel 1 de } \\
\text { negociación } \\
\text { (Arena doméstica B) }\end{array}$} \\
\hline Gremios de negociación
\end{tabular}

Perú-Estados Unidos: expandiendo el win-set

La firma del acuerdo en abril de 2006, entre las partes negociadoras peruana y norteamericana, y su posterior aprobación interna por el congreso peruano pueden entenderse a partir de la proposición de Putnam (1993) de la siguiente manera: la propuesta total del acuerdo firmado en el nivel 1 de negociación encontró respaldo suficiente de actores del nivel 2 de negociación peruano para su firma y aprobación por parte del congreso de ese país. Entendiendo al nivel 2 como la esfera local en la que gremios, sindicatos, sociedad civil y organismos de control 
político actúan en función de intereses específicos, el resultado frente a la aprobación local del documento negociado en el nivel 1 puede representarse en la forma de una balanza que logró agrupar en uno de sus extremos la suficiente cantidad de actores a favor de este para superar al lado antagónico. Esto fue logrado por parte de los agentes del nivel 1 a partir de la expansión del win-set hasta que una cantidad suficiente de actores de presión ofreciera su respaldo a los compromisos establecidos.

La oposición proveniente de partidos de izquierda (Socialista y Nacionalista Peruano a la cabeza), del sindicalismo (CGTP, CNT, CTP, como las representantes más poderosas), la Convención Nacional del Agro Peruano (COnVeagro) y algunos otros sectores como el Colegio Médico del Perú, la Coordinadora de Derechos Humanos y la Campaña Peruana frente al TLC y el ALCA fue insuficiente para bloquear su aprobación en el órgano legislativo local.

Sin embargo, durante el 2007, dada la nueva distribución de sillas en el congreso de Estados Unidos, la balanza del nivel 2 norteamericano no logró inclinarse a favor del acuerdo para su aprobación en el órgano legislativo. Organizaciones sindicales como AFL-CIO y Change to Win, y algunas ONG como Public Citizen, ejercieron presión sobre representantes del partido demócrata en el congreso estadounidense, demandando la revisión de asuntos específicos de los textos (Public Citizen, 2007). Paralelamente, actores de la oposición peruana mantuvieron comunicaciones oficiales con estos mismos congresistas para impulsar la revisión de los asuntos en cuestión.

Volviendo a Putnam (1993), el tamaño de los win-sets del nivel 2 está condicionado por i) la distribución de poder, preferencias y posibles coaliciones entre elementos del nivel 2; ii) las instituciones políticas del nivel 2, y iii) las estrategias de los agentes negociadores del nivel 1. En este caso, la imposibilidad de una aprobación inmediata del acuerdo se dio por la incongruencia entre los niveles 1 y 2 de negociación dada la distribución de poder, preferencias y coaliciones entre elementos del nivel 2 norteamericano. Las decisiones de los agentes del nivel 1 serían fundamentales para satisfacer a los actores de presión norteamericanos y redistribuir el peso de la balanza estadounidense a favor de la aprobación. 
El bloqueo demócrata en el congreso obligó a las partes negociantes del acuerdo — gobiernos de George W. Bush y de Alan García- a establecer enmiendas al documento firmado, y al gobierno aprista a establecer planes y garantías para el cumplimiento de las obligaciones demandadas por la oposición, impuestas por el protocolo modificatorio. Ninguno de los gobiernos ofreció resistencia a ello. La aceptación de parte del Gobierno peruano a las exigencias y su expresa posición de compromiso resultaron ser satisfactorias para mayorías suficientes (Swanson, 2007). Entre tanto, partidos republicano y demócrata establecieron una alianza política interna que, bajo la inclusión obligatoria de asuntos neurálgicos ${ }^{26}$ en las negociaciones presentes y sucesivas de acuerdos comerciales, permitiera destrabar la aprobación de acuerdos futuros y en vilo (USTR, 2007).

Aprobado el protocolo modificatorio en junio de 2007, la balanza empezó a inclinarse. En Perú, por una parte, el Gobierno insistió entre los sectores de apoyo sobre el hecho de que las adendas vinculadas a temas laborales, de propiedad intelectual y de medio ambiente no cambiaban el fondo del texto firmado inicialmente. Por otra parte, varios sectores de la oposición local fueron asumiendo posiciones divergentes. La divergencia más notoria se dio dentro del sindicalismo. Mientras que la CGTP mantuvo una posición firme, la CUT fue disminuyendo la intensidad de las críticas y, no obstante su inconformidad con varios aspectos del acuerdo, desde mediados del segundo semestre de 2007 ofreció reconocimientos explícitos sobre la conveniencia y favorabilidad de los ajustes realizados al gobierno del entonces presidente García. Por su parte, la CTP ofreció apoyo al acuerdo con las modificaciones establecidas y emprendió duras críticas contra sectores opositores del sindicalismo ${ }^{27}$.

En Estados Unidos, el acuerdo bipartidista sirvió para destrabar el proceso. Durante el periodo transcurrido entre la aprobación del protocolo modificatorio y la aprobación final del acuerdo en el congreso norteamericano, la divergencia de posiciones entre las ONG y organi-

\footnotetext{
26 Los ya citados i) propiedad intelectual; ii) agricultura; iii) medio ambiente; iv) inversión extranjera, y v) derechos laborales.

27 Manifestación expresada tras reunión de representantes empresariales con miembros del congreso de Estados Unidos (CONFIEP, 06 de agosto de 2007).
} 
zaciones sindicales fue evidente. A mediados del segundo semestre del 2007, una última exigencia fue impuesta por sectores sindicales norteamericanos y sus representantes demócratas: la aprobación por parte del legislativo de una extensión del Programa de Asistencia Transicional (Transitional Adjustment Assistance — TAA) para lograr la disposición de compensaciones dirigidas a los trabajadores estadounidenses que puedan verse afectados por la suscripción del acuerdo. Al cierre del 2007, por una parte, Change to Win y Public Citizen mantenían su postura opositora. Por otra, sin embargo, AFLCIO manifestaba su satisfacción con los cambios (Swanson, 2007).

Nancy Pelosi, presidenta de la Cámara de Representantes, y Charles Rangel, presidente de la Comisión de Vías y Arbitrios de la Cámara, formaron parte del grupo de congresistas demócratas que ofrecieron su apoyo al acuerdo con Perú tras la inclusión del protocolo modificatorio y la aprobación de la ampliación al TAA: el nuevo acuerdo resultaría ubicándose dentro del win-set del nivel 2 norteamericano. Tras ser aprobado en la Cámara en noviembre de 2007 y en el Senado en diciembre del mismo año, el acuerdo negociado logró su ratificación final. Tras meses de implementación de la legislación requerida, y a pesar de la insistente oposición de algunos movimientos sociales en la arena local, los conflictos localizados - con resultados violentos- producto de dichas tensiones con el gobierno de García (Cameron, 2011) y el mantenimiento de posiciones contrarias por parte de Change to Win y Public Citizen, el acuerdo entró en función en febrero de 2009.

Colombia-Estados Unidos: imposibilidad política

Así como en el caso de Perú y Estados Unidos, la firma del acuerdo entre las partes negociadoras colombiana y norteamericana y su posterior aprobación interna por Congreso y Corte Constitucional colombianos puede entenderse así: la propuesta total del acuerdo firmado en el nivel 1 encontró respaldo suficiente por parte de actores del nivel 2 colombiano para que se diera su firma y aprobación por parte de Congreso y Corte Constitucional colombianos. 
El gobierno del presidente Uribe supo conseguir el apoyo de los gremios más importantes del país, así como de mayorías en el Congreso de la República (Pulecio, 2005; Silva, 2007). La oposición, proveniente de sectores de los partidos Liberal y Polo Democrático, del sindicalismo (CUT, CGT, CTC), de la CPC, de movimientos sociales como RECALCA, de sectores industriales nacionales (pequeña y mediana industria, así como la farmacéutica nacional) o la iglesia católica, fue insuficiente para bloquear su aprobación en el Congreso.

De manera similar al caso peruano, las dificultades para el acuerdo provinieron del nivel 2 norteamericano. Así como en Perú, la presión opositora logró imponer ajustes a través de la inclusión del protocolo modificatorio.

La aprobación del protocolo aminoró la presión de algunos grupos en la arena colombiana. Ejemplo de esto es el caso de la coalición conformada para evitar la aprobación del acuerdo o en todo caso lograr modificaciones favorables a las cláusulas sobre propiedad intelectual $\left(\right.$ Silva, 2007) ${ }^{28}$. Sin embargo, contrario a lo ocurrido con el acuerdo entre Perú y Estados Unidos, la aprobación de este protocolo con compromisos sobre legislación y salvaguarda de derechos laborales no representó una expansión suficiente del win-set del nivel 2 norteamericano. La presión ejercida por las redes defensoras de derechos laborales logró imponerse desde el ámbito norteamericano para condicionar la aprobación definitiva del acuerdo. A diferencia de la situación para Perú, frente a Colombia la posición de AFL-CIO, el actor de presión en contra más poderoso en la arena doméstica norteamericana, se mantendría en línea con las posiciones de Change to Win y Public Citizen, y con las de las centrales sindicales y ONG colombianas.

Para agosto de 2007 una visita a Perú de congresistas demócratas fue programada con el objeto de revisar el avance en los procesos de legislación e implementación de planes requeridos por el acuerdo, teniendo en consideración las modificaciones incluidas sobre medio ambiente y

\footnotetext{
28 Colación mixta, compuesta por representantes de laboratorios farmacéuticos nacionales, ONG — nacionales e internacionales defensoras del acceso de calidad a servicios de salud y medicamentos-, movimientos sociales y la iglesia católica.
} 
derechos laborales. Las estimaciones para la presentación del acuerdo para su ratificación en Cámaras del legislativo norteamericano estaban dadas para los meses de septiembre u octubre de ese mismo año. Sobre el acuerdo colombiano, sin embargo, las declaraciones de estos congresistas fueron claras: desestimaron cualquier posible ratificación hasta contar con evidencia satisfactoria sobre avances en materia laboral y de derechos humanos (Toner, 2007).

La estrategia de los gobiernos de Bush y Uribe se concentró en i) ofrecer información que demostrara avances en materia de salvaguarda de derechos fundamentales de sindicalistas, ii) insistir, no obstante el alegado compromiso del gobierno colombiano, en la imposibilidad de mayores resultados inmediatos ante la complejidad estructural del problema, y iii) esgrimir el argumento del compromiso político de Estados Unidos con Colombia como principal aliado en una región distanciada.

La estrategia, sin embargo, no daría resultados. Críticas de grupos opositores a la presentación del Gobierno colombiano de lo que consideraron información sesgada, demandas de mayores resultados en materia de derechos fundamentales para los trabajadores y manifestaciones de desaprobación por un trato estigmatizador a sindicalistas y defensores de derechos humanos por parte de altos representantes del Gobierno colombiano (incluido el presidente Uribe) fueron permanentes.

Comisiones de actores proacuerdo y un intenso lobby impulsado por el Gobierno colombiano no encontraron eco suficiente entre las filas demócratas. Invitaciones a políticos y activistas norteamericanos no lograron tampoco expandir suficientemente el win-set del nivel 2 estadounidense. Las posiciones de congresistas, presidentes de Cámara de Representantes y de la Comisión de Vías y Arbitrios de Estados Unidos incluidos, se mantuvieron intactas. La presión por parte de AFL-CIO, base de apoyo fundamental para congresistas clave dentro del debate, se mantuvo durante el periodo de trámite y aprobación frente a sus representantes en la Casa Blanca y en el Senado; así como el trabajo conjunto entre sindicalistas norteamericanos y colombianos, para ejercer presión desde la arena política estadounidense. 


\section{Estructuras e interacciones comparadas: Perú y Colombia}

Tres elementos se diferencian entre las dos experiencias: i) unidad persistente entre agrupaciones defensoras de derechos laborales con respecto a su oposición a la ratificación del acuerdo entre Colombia y Estados Unidos; ii) insistencia sobre la necesidad de mayores resultados frente a la protección de los derechos fundamentales de sindicalistas en el caso colombiano, y iii) desaprobación de la postura del gobierno del presidente Uribe en torno al problema de la violación de los derechos fundamentales de los sindicalistas.

¿Un problema de agencia? Cameron y Tomlin (2000) definen la negociación como un proceso complejo en el que las respuestas están determinadas por la utilidad subjetiva que las partes tengan sobre las alternativas del no acuerdo. Dicha utilidad asignada a las alternativas del no acuerdo determinará los patrones de respuesta de cada cual. ¿Fueron menores las utilidades subjetivas sobre la alternativa de no acuerdo en el caso del Gobierno colombiano? ¿O fue su estrategia desacertada?

\section{Negociadores y utilidades subjetivas}

El reconocimiento de motivaciones y restricciones percibidas por los agentes en torno al proceso de negociación ayudó a definir las utilidades que estos asocian a un no acuerdo. La encuesta — que se anexa— entre académicos peruanos y colombianos permitió explorar los elementos de la proposición sobre utilidades subjetivas, aversión al riesgo y concesiones realizadas (ver el aparte teórico para mayor detalle). Sus resultados fueron confrontados con una revisión de citas y comunicados presentes fundamentalmente en medios de comunicación.

\section{Perú-Estados Unidos: comercio y política}

El caso del gobierno de García va en línea con las expectativas del modelo. Los indicadores diseñados para evaluar la utilidad subjetiva que se le asignase a la alternativa de no acuerdo demostraron altos grados de percepción de utilidad sobre este. 
Por su parte, los indicadores diseñados para evaluar la aversión al riesgo frente a la opción de alcanzar esas ganancias y la disposición de ponerlo en riesgo también respondieron a las expectativas del modelo: las respuestas del Gobierno peruano frente a las demandas sobre derechos laborales fueron calificadas como razonables o positivas ${ }^{29}$, en tanto que se reconoció en la percepción del Gobierno peruano una fuerte necesidad política de responder a las demandas en función de la aprobación del acuerdo ${ }^{30} \mathrm{y}$ un alto nivel de disposición a ceder frente a ellas.

Finalmente, en lo referente a las concesiones ofrecidas durante el proceso de ajuste para obtener el acuerdo, entendiendo la suficiencia de concesiones ofrecidas según la percepción del nivel de satisfacción de la contraparte norteamericana con respecto a las respuestas, lo obtenido concuerda con las expectativas: a las preguntas sobre el nivel de satisfacción de la contraparte norteamericana en materia de legislación impulsada sobre derechos laborales para dar respuesta a las demandas exigidas, entre el $71 \%$ y $86 \%$ de las respuestas se situó en los valores más altos de la escala. Por su parte, a las preguntas sobre el nivel de satisfacción de la contraparte norteamericana en materia de seguimiento a la aplicación y al cumplimiento de las modificaciones formales aplicadas sobre derechos laborales, el total de las respuestas situó este nivel por encima de un valor de tres (en una escala de 1 a 5), distribuyéndose las respuestas mayoritariamente entre los valores 3 y 4 de la escala.

De los resultados de este ejercicio pudo concluirse que: i) la percepción del Gobierno peruano sobre la utilidad del acuerdo durante el periodo en evaluación fue alta; ii) su posición frente a los requerimientos de la contraparte norteamericana fue abierta antes que problemática; iii) la disposición manifiesta de dar respuesta a esos requerimientos fue positiva y razonable, aunque frente a las demandas locales la disposición fuese menos clara ${ }^{31}$, y iv) su nivel de respuesta fue satisfactorio para la contraparte.

\footnotetext{
29 Las opciones de respuesta fueron "agresiva", "negativa”, “indiferente”, "razonable", "positiva", "inexistente", "otro".

30 Las opciones de respuesta fueron "inaceptable", "innecesario" y "necesario", con posiciones intermedias (de relativa aceptabilidad o necesidad), y "otros".

31 Las respuestas van en concordancia con el trato interno que el Gobierno central peruano
} 
Colombia-Estados Unidos: concesiones vs. lucha antiterrorista

El caso del gobierno de Álvaro Uribe, en cambio, no responde a las expectativas del modelo. Por una parte, los indicadores diseñados para evaluar la utilidad subjetiva que se le asignase a la alternativa de no acuerdo demostraron altos grados de percepción de utilidad sobre este. Sin embargo, la situación en las demás dimensiones fue diferente.

Por una parte, están los indicadores diseñados para evaluar la aversión al riesgo frente a la opción de alcanzar esas ganancias y la disposición de ponerlo en riesgo: sobre la posición del Gobierno colombiano frente a las demandas de la contraparte con respecto a los derechos laborales fundamentales se indicó mayoritariamente que fueron entendidas como exageradas y en menor medida como innecesarias, en tanto que un $83 \%$ de las respuestas reconoció el nivel de disposición del Gobierno de ceder a las demandas como bajo o medio. Sobre la percepción del Gobierno colombiano frente a la necesidad política de responder a las demandas para la aprobación del acuerdo, la dispersión de las respuestas fue alta ${ }^{32}$.

Por otro lado, las respuestas sobre la posición expresa del Gobierno frente a las demandas en materia de derechos laborales, específicamente sindicales, fueron percibidas en alto grado como agresivas o negativas y en grado menor como indiferentes, mientras tan solo un $17 \%$ las percibió como razonables.

Finalmente, en lo referente a concesiones ofrecidas en el proceso de ajuste para obtener el acuerdo, entendiendo la suficiencia de concesiones ofrecidas según la percepción del nivel de satisfacción de la contraparte norteamericana con respecto a las respuestas, lo obtenido fue lo siguiente: a las preguntas sobre el nivel de satisfacción de la contraparte norteamericana en materia de legislación impulsada, y de seguimiento, aplicación y cumplimiento de las modificaciones formales aplicadas sobre derechos laborales para dar respuesta a las

dio a manifestaciones públicas de movimientos sociales de la oposición (Cameron, 2011).

$32 \quad 17 \%$ la reconoció como inaceptable, un $8 \%$ como problemática, un 33\% como innecesaria y un $42 \%$ como necesaria. 
demandas exigidas, entre el $67 \%$ y $83 \%$ de las respuestas se situó en los valores más bajos de la escala.

De los resultados de este ejercicio puede concluirse que: i) la percepción del Gobierno colombiano sobre la utilidad del acuerdo durante el periodo en evaluación fue alta; ii) su posición frente a los requerimientos de la contraparte norteamericana, sin embargo, fue problemática; iii) la disposición manifiesta de dar respuesta a esos requerimientos fue afectada por la incapacidad del Gobierno de abordar la necesidad política de hacerlo y por su posición frente al problema del cual provenían los reclamos, y iv) su nivel de respuesta, en consecuencia, resultó insatisfactorio para la contraparte.

\section{Utilidades subjetivas comparadas: Perú y Colombia}

Según Cameron y Tomlin (2000), los elementos clave en la construcción de utilidades subjetivas se encuentran en el marco institucional en el que las partes operen. En cuanto al Gobierno peruano, la relación entre utilidad subjetiva, aversión al riesgo y concesiones responde con claridad a las expectativas. A pesar de su posición frente al acuerdo en momentos de campaña, García abordó una estrategia diferente una vez asumida la presidencia: continuar las políticas de Toledo en materia económica y comercial le garantizaría la consolidación y el mantenimiento de una coalición de Gobierno estable (Cameron, 2011). En este sentido, la asignación de una utilidad subjetiva frente a la posibilidad de no acuerdo respondió a requerimientos propios del marco institucional en el que García construía su estrategia. En línea con ello, sus respuestas buscaron garantizar las concesiones suficientes para la ratificación del acuerdo.

En el caso de Uribe la relación entre utilidad subjetiva asignada a la posibilidad de no acuerdo, la aversión al riesgo y las concesiones otorgadas precisan ser aclaradas. Silva (2007), reafirmando argumentos de Pulecio (2005), señala cómo la estrategia del Gobierno colombiano hacia el exterior durante el proceso de negociación no fue acertada, en tanto ignoró la política doméstica estadounidense: "desconoció el papel del partido Demócrata en el Congreso y la relación entre los 
sectores que ellos representan con sectores colombianos que hacen oposición al gobierno de Uribe" (Silva, 2007, p. 130).

Sin embargo, durante el posterior proceso de ratificación, y especialmente ante la presencia de mayorías demócratas en ambas Cámaras desde 2007, pudo identificarse un intento de atender las demandas de la oposición para conseguir la aprobación. ¿Por qué esos avances no fueron satisfactorios?

Así como el gobierno de Uribe buscó demostrar logros en materia de salvaguarda de derechos fundamentales del trabajador, continuó defendiendo el argumento de la necesidad estadounidense de responder al compromiso político con Colombia - principal aliado estratégico en una región políticamente distanciada de Washington-, mientras se reforzaba el llamado a apoyar la política de Seguridad Democrática que el Gobierno implementaba como camino para lograr la prosperidad nacional.

La dificultad de parte del Gobierno colombiano para solucionar la complejidad de los obstáculos presentes puede encontrarse entonces en la persistencia de esta estrategia que, como indica Pulecio (2005), se fundó en la idea de consolidar a Colombia como aliado estratégico estadounidense en la región, a partir de la reafirmación de afinidades políticas entre ambos gobiernos (Uribe y Bush) en materia de lucha global contra el terrorismo ${ }^{33}$, porque, como señala Tickner (2007), las tendencias observadas en Washington frente al TLC y al Plan Colombia, a partir de la nueva distribución de puestos en Cámaras norteamericanas desde las elecciones de 2006, indicaron un viraje en su política interna dentro de la cual se apreció "una reducción dramática en la receptividad que tiene el discurso bélico del presidente Uribe y un desinterés general de preservar la relación 'especial' con Colombia" (p. 108).

\footnotetext{
33 "Dichas afinidades se materializarían en acuerdos estratégicos en torno a la lucha contra el terrorismo (Plan Colombia y Plan Patriota) y la firma del TLC", afirma Pulecio (2005) sobre la posición del Gobierno colombiano al respecto.
} 
Dicha reducción en la receptividad se mantendría durante buena parte del periodo en revisión. Sin embargo, antes que volcar todos sus esfuerzos para satisfacer las demandas de la oposición, el Gobierno siguió jugando a dos bandos, satisfaciendo parcialmente las demandas demócratas mientras apostaba al énfasis de su argumento ante representantes de los dos partidos, Republicano y Demócrata, de único aliado estadounidense en el hemisferio.

La posición interna del Gobierno en contra de sindicalistas y defensores de derechos humanos, su estigmatización, así como el seguimiento a miembros de estas agrupaciones desde el Departamento Administrativo de Seguridad (DAS) enmarcados dentro de la política de Seguridad Democrática del Gobierno colombiano son elementos que permiten entender la encrucijada ante la cual el presidente Uribe se encontraba - le hablan así a la literatura sobre política exterior nacional: distintas dimensiones de la política exterior pueden, ante coyunturas específicas, entrar en tensión y moldearse a partir de presiones externas entre sí-. La obtención del acuerdo era altamente valorada, pero aceptar la totalidad de concesiones exigidas por la oposición demócrata contravendría principios funcionales de su política bandera de lucha antiterrorista. Así las cosas, su estrategia fue la mencionada: respuestas parciales y posicionamiento como aliado. La ratificación por esta línea parecería sellada: al menos ante mayorías demócratas, no podría lograrse bajo una presidencia de Uribe Vélez.

La situación para el periodo posterior al revisado resultó distinta. A nuevas mayorías republicanas en la Cámara de Representantes desde 2011, se le sobrepone la mayor crisis económica vivida por Estados Unidos en más de siete décadas, y los inicios de una campaña presidencial estadounidense marcada por la insatisfacción del sindicalismo - particularmente manifiesta en AFL-CIO- y el enfriamiento de sus relaciones con el partido Demócrata. Dichas condiciones constituyen un reajuste de la estructura de oportunidad política que marcó el proceso de presión para el caso colombiano. La evidencia permite reconocer cómo tácticas y discursos de la oposición sindical norteamericana frente a los TLC (los mencionados y todos en general) una vez iniciada la crisis viraron progresivamente hacia un mayor énfasis 
— sin desatender sus preocupaciones anteriormente esgrimidas, particularmente en lo referido al caso colombiano- sobre los efectos nocivos para la mano de obra estadounidense de la promoción de este tipo de políticas. En ese contexto, sin embargo, disposición y capacidad de la contraparte negociante de dar respuesta a las exigencias provenientes de la arena local norteamericana siguieron siendo fundamentales para la aprobación de los documentos firmados. Así lo demuestra la experiencia con el nuevo Gobierno colombiano: discurso y acciones de Santos, tanto en materia comercial como de seguridad, derechos humanos y protección laboral cambiaron de manera importante (Morales \& Tickner, 2015; Revista Semana, 2011; 2012; El País, 2011). Al hacerlo generó confianza y nuevos adeptos, lo que logró el debilitamiento de la coalición contradictora de su arena local y ayudó aún más al debilitamiento de la coalición trasnacional misma ${ }^{34}$. Así, con nuevas condiciones estructurales y una renovada postura política, el gobierno de Santos vería la expansión del win-set del nivel 2 estadounidense. Las contradicciones vividas por su antecesor no resultarían siendo tales para este nuevo gobernante.

\section{Conclusiones}

La reconstrucción de los procesos de ratificación de ambos acuerdos encontró divergencias por parte de la oposición en: i) la persistente unidad entre agrupaciones defensoras de derechos laborales (en las arenas doméstica e internacional) con respecto a su oposición a la ratificación del acuerdo entre Colombia y Estados Unidos; ii) la insistencia conjunta de estos agentes sobre la necesidad de mayores resultados en materia de derechos fundamentales de la mano de obra en el caso colombiano, y iii) la desaprobación de la postura del gobierno del presidente Uribe en torno al problema de violación de derechos fundamentales de sindicalistas. Por su parte, se encuentran divergencias entre los gobiernos de Uribe y García en la consistencia en el caso peruano entre utilidades subjetivas sobre la posibilidad de

\footnotetext{
34 Si bien algunas voces del sindicalismo colombiano mantendrían mensajes de insatisfacción y alerta, otras tantas aceptarían discurso y acciones del nuevo mandatario como satisfactorias.
} 
no acuerdo y la disposición de otorgar concesiones satisfactorias, y la inconsistencia en el caso colombiano dado el conflicto percibido entre el tipo de concesiones reclamadas y los principios funcionales de la política bandera antiterrorista del presidente Uribe.

Tabla 2. Los niveles 1 y 2 de negociación: estructura, interacción y agencia

\begin{tabular}{|c|c|c|c|}
\hline Hipótesis País & Estados Unidos & Colombia & Perú \\
\hline $\begin{array}{l}\text { El tamaño del win- } \\
\text { set depende de la } \\
\text { distribución de } \\
\text { poder, preferencias } \\
\text { y posibles } \\
\text { coaliciones } \\
\text { entre elementos } \\
\text { del "nivel } 2 \text { de } \\
\text { negociación": a } \\
\text { menor el costo de } \\
\text { no acuerdo para } \\
\text { estos elementos, } \\
\text { menor el win-set. }\end{array}$ & $\begin{array}{l}\text { A partir de } 2007, \\
\text { nueva distribución } \\
\text { de sillas en } \\
\text { el Congreso } \\
\text { con mayorías } \\
\text { demócratas, de } \\
\text { fuerte apoyo } \\
\text { proveniente del } \\
\text { sindicalismo. } \\
\text { Esta oposición } \\
\text { condiciona } \\
\text { aprobación a } \\
\text { la inclusión } \\
\text { de enmiendas. } \\
\text { Gobierno y bancada } \\
\text { republicanos } \\
\text { deben acceder } \\
\text { a la inserción } \\
\text { de enmiendas a } \\
\text { acuerdos en aras de } \\
\text { lograr la aprobación. }\end{array}$ & $\begin{array}{l}\text { Coalición anti- } \\
\text { TLC políticamente } \\
\text { menos poderosa } \\
\text { que coalición pro- } \\
\text { TLC en la arena } \\
\text { local. Enmiendas } \\
\text { impulsadas desde } \\
\text { el Legislativo } \\
\text { norteamericano } \\
\text { son aceptadas por } \\
\text { coalición colombiana } \\
\text { doméstica pro-TLC. } \\
\text { No se reconocen } \\
\text { suficientes en lo } \\
\text { relativo a asuntos } \\
\text { laborales y de } \\
\text { derechos humanos } \\
\text { por parte de la } \\
\text { coalición trasnacional } \\
\text { anti-TLC. }\end{array}$ & $\begin{array}{l}\text { Coalición anti- } \\
\text { TLC políticamente } \\
\text { menos poderosa } \\
\text { que coalición } \\
\text { pro-TLC en la } \\
\text { arena local. } \\
\text { Enmiendas } \\
\text { impulsadas desde } \\
\text { el Legislativo } \\
\text { norteamericano } \\
\text { son aceptadas } \\
\text { tanto por } \\
\text { coalición peruana } \\
\text { doméstica pro- } \\
\text { TLC como por } \\
\text { segmentos de } \\
\text { la coalición } \\
\text { trasnacional } \\
\text { anti-TLC. }\end{array}$ \\
\hline $\begin{array}{l}\text { El tamaño del } \\
\text { win-set depende de } \\
\text { las instituciones } \\
\text { políticas del "nivel } \\
2 \text { de negociación": } \\
\text { a mayor poder } \\
\text { del Estado en } \\
\text { términos de } \\
\text { autonomía frente } \\
\text { a presiones } \\
\text { domésticas, más } \\
\text { débil será su } \\
\text { posición relativa } \\
\text { de negociación } \\
\text { en la arena } \\
\text { internacional. Y } \\
\text { viceversa. }\end{array}$ & $\begin{array}{l}\text { Mayorías } \\
\text { demócratas } \\
\text { desde } 2007 \text { con } \\
\text { puestos clave } \\
\text { en el Legislativo } \\
\text { (presidencias } \\
\text { de la Cámara de } \\
\text { Representantes y } \\
\text { de la Comisión de } \\
\text { Vías y Arbitrios de } \\
\text { esa misma Cámara } \\
\text {-comisión } \\
\text { que define } \\
\text { programación para } \\
\text { la presentación } \\
\text { del proyecto en } \\
\text { Cámaras-). }\end{array}$ & $\begin{array}{l}\text { Gobierno central } \\
\text { colombiano } \\
\text { acepta protocolo } \\
\text { modificatorio } \\
\text { condicionante. } \\
\text { Enmiendas alineadas } \\
\text { con intereses de } \\
\text { sectores domésticos } \\
\text { anti-TLC vienen } \\
\text { presionadas por la } \\
\text { vía trasnacional. } \\
\text { Respuesta a demandas } \\
\text { persistentes sobre } \\
\text { asuntos laborales y de } \\
\text { derechos humanos, } \\
\text { sin embargo, } \\
\text { no se encuentra } \\
\text { satisfactoria por } \\
\text { parte de la oposición } \\
\text { trasnacional. }\end{array}$ & $\begin{array}{l}\text { Gobierno } \\
\text { central peruano } \\
\text { acepta protocolo } \\
\text { modificatorio } \\
\text { condicionante. } \\
\text { Enmiendas } \\
\text { alineadas } \\
\text { con intereses } \\
\text { de sectores } \\
\text { domésticos } \\
\text { anti-TLC vienen } \\
\text { presionadas } \\
\text { por la vía } \\
\text { trasnacional. }\end{array}$ \\
\hline
\end{tabular}




\begin{tabular}{|c|c|c|c|}
\hline Hipótesis País & Estados Unidos & Colombia & Perú \\
\hline $\begin{array}{l}\text { El tamaño del } \\
\text { win-set depende } \\
\text { de las utilidades } \\
\text { subjetivas de } \\
\text { los agentes } \\
\text { negociadores } \\
\text { del "nivel } 1 \text { de } \\
\text { negociación". }\end{array}$ & $\begin{array}{l}\text { "Nivel } 1 \text { de } \\
\text { negociación" } \\
\text { acepta enmiendas, } \\
\text { procurando } \\
\text { expansión del win- } \\
\text { set que permita la } \\
\text { aprobación de los } \\
\text { acuerdos. }\end{array}$ & $\begin{array}{l}\text { "Nivel } 1 \text { de } \\
\text { negociación" } \\
\text { acepta enmiendas, } \\
\text { procurando una } \\
\text { expansión del win- } \\
\text { set que permita } \\
\text { la aprobación del } \\
\text { acuerdo. Sin embargo, } \\
\text { ante persistencia de } \\
\text { demandas no parece } \\
\text { haber consistencia } \\
\text { entre utilidades } \\
\text { subjetivas frente al no } \\
\text { acuerdo, aversión al } \\
\text { riesgo y concesiones. } \\
\text { Problema en respuesta } \\
\text { para gobierno radica } \\
\text { en naturaleza de } \\
\text { demandas. Win-set } \\
\text { no se expande lo } \\
\text { necesario. }\end{array}$ & $\begin{array}{l}\text { "Nivel } 1 \text { de } \\
\text { negociación" } \\
\text { acepta } \\
\text { enmiendas, } \\
\text { llevando a } \\
\text { una expansión } \\
\text { del win-set } \\
\text { que permita la } \\
\text { aprobación del } \\
\text { acuerdo. Hay } \\
\text { consistencia } \\
\text { entre utilidades } \\
\text { subjetivas frente } \\
\text { al no acuerdo, } \\
\text { aversión al riesgo } \\
\text { y concesiones. }\end{array}$ \\
\hline
\end{tabular}

Fuente: Elaboración propia.

Dos acuerdos bilaterales más llevados adelante por Estados Unidos estuvieron en juego durante el periodo: los negociados con Corea del Sur y Panamá. La prolongación en la aprobación de ambos por el Congreso estadounidense acompañó la del caso colombiano, por lo que su mención es necesaria: los argumentos de peso esgrimidos desde Estados Unidos en contra del acuerdo con Corea (fundamentalmente las asociaciones sindicales ya mencionadas y el partido demócrata en la arena norteamericana) se centraron en preocupaciones de índole económica-comercial; no en cambio en asuntos relacionados con eventuales violaciones de derechos fundamentales o laborales en el país asiático. Siendo así, su aprobación no acompañó la del acuerdo con Perú, en tanto la capacidad exportadora del mercado asiático ${ }^{35}$ constituiría una amenaza que el peruano (o el colombiano) no llegaría a alcanzar. Su aprobación, en cambio, se daría tras la renegociación en 2010 de algunos apartes que nivelarían el terreno para el sector automotriz y los trabajadores del mercado norteamericano.

\footnotetext{
35 Ciertos mercados específicos. Además de particulares condiciones alcanzadas por Corea en la negociación para el ingreso de bienes, servicios y capital norteamericano a su mercado.
} 
La prolongación de una aprobación para el acuerdo con Panamá durante el periodo en revisión, por su parte, encontró su mayor inconveniente en el polémico nombramiento del político Miguel González como presidente de la Asamblea Nacional. Al ser requerido por la justicia norteamericana para ser juzgado por el asesinato de un militar estadounidense, miembros del mismo gobierno del presidente Bush, del Congreso norteamericano e incluso candidatos a la presidencia para el periodo a iniciarse en 2009 condicionaron la aprobación. Aparte de esto, asuntos referidos a la legislación fiscal y laboral en el país centroamericano se constituyeron en los principales puntos de discusión norteamericana sobre el acuerdo, evidenciándose, sin embargo, una menor intensidad en el ejercicio de oposición que en el caso del acuerdo colombiano.

Señalado lo anterior, cabe decir que desestimar preocupaciones de índole comercial por parte de los actores de presión norteamericanos en contra del acuerdo con Colombia, así como en contra de cualquier otro acuerdo, no puede entrar en consideración. Estas fueron expresadas tanto en el caso de la negociación con Colombia, como en las negociaciones con los demás. La divergencia, sin embargo, entre el caso peruano y el coreano (uno aprobado y otro no por cuestiones netamente económicas), así como la recurrencia de y la insistencia sobre distintos argumentos esgrimidos por la oposición norteamericana para cada uno de los casos permiten entender las negociaciones como casos independientes sobre los cuales sí pesaron motivaciones exclusivas para su eventual aprobación. Esto se condice con argumentos de Anner (2008) o Keck y Sikkink (1998) según los cuales motivaciones instrumentales, ideológicas o morales pueden entrar conjunta o independientemente en juego para la activación de presiones de redes trasnacionales ante coyunturas como estas, a partir de preocupaciones particulares. Además, da cuenta de cómo buscar exclusivamente en motivaciones materiales la explicación a la conformación de diversas coaliciones de frente a estos acuerdos, como Leiteritz (2006) señala, impone visiones sesgadas sobre la política internacional, la política misma y su actor fundamental.

Por otro lado, la explicación desde los discursos y la presión trasnacional por el respeto a los derechos fundamentales de los trabajadores en los países peruano y colombiano, la diferencia en el nivel de violación 
de sus derechos en los dos casos, o la satisfacción obtenida de sus demandas como camino inmediato para dar cuenta de aprobaciones y divergencias entre los casos colombiano y peruano son centrales y sin embargo insuficientes. Se corre el riesgo de asumir satisfacciones plenas y de no dar cuenta de la expansión de win-sets por la vía de debilitamientos de coaliciones. Pero pasa sin duda por alto dilemas que en el camino un gobernante pueda afrontar. Atender con detalle al juego de García y de Uribe y de la percepción de las contrapartes da cuenta de la relevancia de esta variable en la explicación general.

Las negociaciones comerciales aquí expuestas muestran cómo la política exterior adelantada por un gobierno puede llevar, puestas en tensión desde afuera dos de sus líneas centrales Dusso \& Milanese (2012), a contradicciones que imposibiliten decisiones deseadas por un gobernante. Estos casos permiten perfeccionar una apuesta valiosa para el estudio y sistematización de procesos de negociación comerciales: aquella sobre las utilidades subjetivas de los actores negociantes. Lo hace al reconocer dilemas para distintos gobernantes, dando vida al seguimiento de procesos de negociación y política internacional que reconozcan no solo el juego de doble nivel, sino el juego de líneas de política exterior simultáneas, que frente a estructuras de oportunidad política dan cuenta de cómo, antes que rectas paralelas, son líneas sinuosas que con frecuencia van encontrándose. Esta comparación es un llamado a problematizar entonces los supuestos suyacentes a los modelos de la política y de negociación internacional. Si bien son útiles para abordar situaciones referentes a la materia, evidencian limitaciones que los avances de la psicología cognitiva (desde Thaler (1993), por ejemplo) y de la sociología económica (Beckert, 2002, 2016) podrían ayudar a solventar. El caso de Uribe invita a explorar las causas y sesgos de sus evaluaciones — asunto que persiguen la sociología económica y la psicología experimental— pero además lo que él mismo hace de ellas desde sus exigencias normativas en particular ${ }^{36}$. Una oportunidad para teorizar sobre política exterior y negociaciones internacionales más allá del supuesto del maximizador racional.

\footnotetext{
36 Hay aquí algunas exploraciones interesantes sobre una heurística moral desde el campo de la filosofía experimental, por ejemplo (Appiah, 2008).
} 


\section{Anexo: Utilidades subjetivas y respuesta. Resultados agregados de encuestas a académicos}

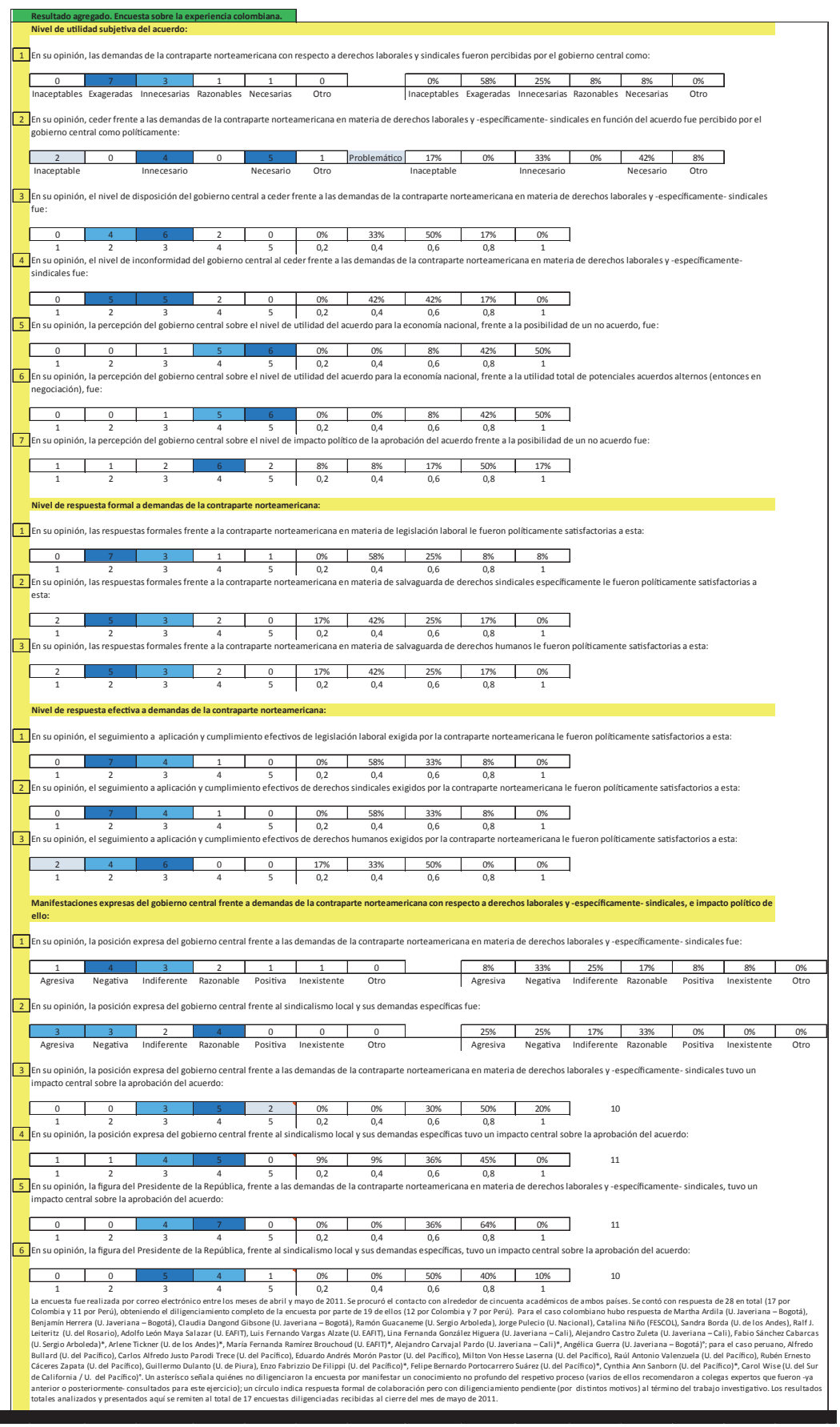




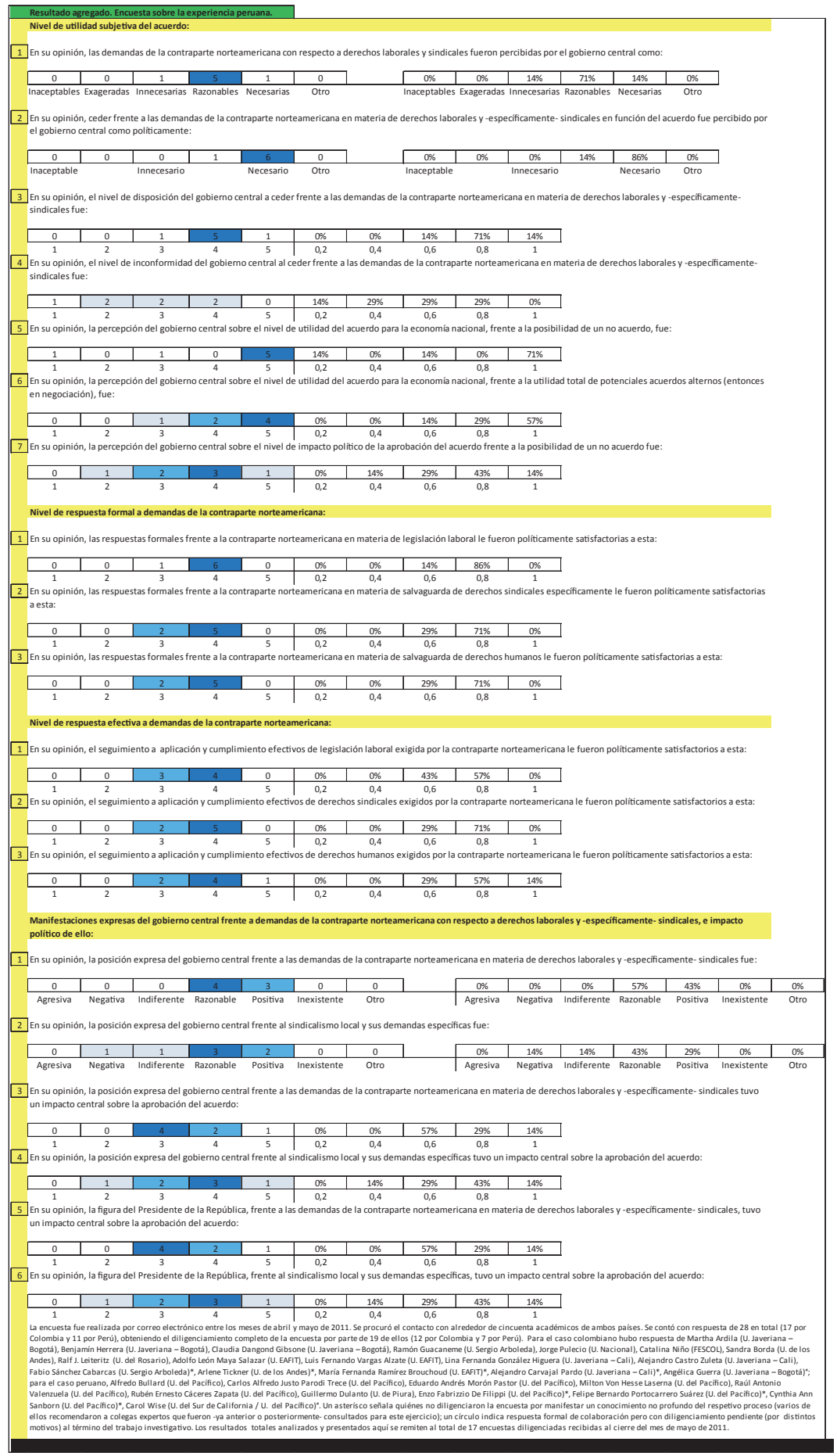




\section{Referencias}

Anner, M. (2002). Between economic nationalism and transnational solidarity: Labor responses to internationalization and industrial restructuring in the Americas. Ponencia presentada en el Congreso Anual de la American Political Science Association, Boston.

Anner, M. (2008). Meeting the challenges of industrial restructuring: Labor reform and enforcement in Latin America. Latin American Politics and Society, 50(2), 33-65.

Appiah Kwame, A. (2008). Experiments in ethics. Cambridge, MA: Harvard University Press.

Beckert, J. (2002). Beyond the Market. The Social Foundations of Economic Efficiency. Princeton: Princeton University Press.

Beckert, J. (2016). Imagined Futures. Fictional Expectations and Capitalist Dynamics. Cambridge, MA: Harvard University Press. de la Cadena, A. E. (2008). Bancadas, regiones y ausentismo. El voto del Congreso colombiano en el TLC con los Estados Unidos. Bogotá: Ediciones Uniandes.

Cameron, M. (2011). The left turn that wasn't. En S. Levistky \& K. Roberts (Eds.), The resurgence of the Latin American left (pp. 375-397). Baltimore: John Hopkins University Press.

Cameron, M., \& Tomlin, B. (2000). The making of NAFTA: How the deal was done. Ithaca, NY: Cornell University Press.

Cárdenas, M. E. (2006). Treinta años de sindicalismo en Colombia: vicisitudes de una transformación. En F. Leal (Ed.), En la encrucijada: Colombia en el siglo XXI (PP. 233-261). Bogotá: Editorial Norma.

Compa, L. (2004). Trade unions, NGOs, and corporate codes of conduct. Development in Practice, 8(3), 5-7.

Center for Responsive Politics. (s.f.). AFL-CIO. Recuperado de http:/ / www. opensecrets.org/orgs/summary.php? $\mathrm{id}=\mathrm{d} 000000088$

Center for Responsive Politics. (11 de septiembre de 2017). Labor. Recuperado de http:/ / www.opensecrets.org/industries/indus.php?ind $=\mathrm{P}$ CONFIEP. (06 de agosto de 2007). Nota de prensa. Recuperado de http:/ / www. confiep.org.pe/articulos/comunicaciones/empresarios-peruanos-sereunen-con-congresistas-de-los-eeuu

Cook, M. L. (2007). The politics of labor reform in Latin America: Between flexibility and rights. University Park: Pennsylvania State University Press. 
Druckman, D. (1986). Stages, turning points and crises: Negotiating military base-rights, Spain and the United States. Journal of Conflict Resolution, 30, 327-360.

El País. (05 de mayo de 2012). Nota de prensa. Recuperado de http://www. elpais.com.co/elpais/economia/conozca-medidas-comprometecolombia-para-firmar-tlc

Elliott, K. A. (1998). International labor standards and trade: What should be done? En J. Schott (Ed.), Launching new global trade talks: An action agenda (pp. 171-175). Washington: Institute for International Economics.

Evans, P., \& Anner, M. (2004). Building bridges across a double divide: alliances between us and Latin American labour and NGOs. Development in Practice, 14(1/2), 34-47.

Fernández Dusso, J. J., \& Milanese, J. P. (2012). La política exterior colombiana a la luz de los tratados ratificados por el Congreso entre 1968 y 2011. En J. Stefan (Ed.), Colombia: ¿Una potencia en desarrollo? Escenarios y desafíos para su política exterior (pp. 409-429). Bogotá: Konrad Adenauer Stiftung.

Frundt, H. (1998). Trade conditions and labor rights: US initiatives, Dominican and Central American responses. Gainesville: University Press of Florida.

Frundt, H. (2002). Central American unions in the era of globalization. Latin American Research Review, (3), 13-53.

Gassek, S. (2008). The US-Colombia free trade agreement: A Capitol Hill Conversation. Washington: Wilson Center.

Garay, L. G., de Lombaerde, P., \& Barberi, F. (2011). Negotiating the Colombia-US FTA: A Colombian perspective. En S. Bilal, P. de Lombaerde \& D. Tussie (Eds.), Asymmetric trade negotiations (pp. 137-165). Aldershot: Ashgate.

Garay, L. J., Barberi, F., \& Espinosa, A. (2004). El agro colombiano frente al TLC con los Estados Unidos. Bogotá: Ministerio de Agricultura y Desarrollo Social de Colombia.

Greenhouse, S. (7 de enero de 2009) Labor calls for unity after years of division. The New York Times.

Haugaard, L. (junio 2008). The other half of the truth: Searching for truth, justice and reparations for colombia's victims of paramilitary violence. Recuperado de http://www.lawg.org/storage/documents/other\%20half.pdf

Hiscox M. J. (2001). Class versus industry cleavages: Inter-industry factor mobility and the politics of trade. International Organization, 55(1), 1-46. 
Hiscox M. J. (2008). The domestic sources of foreign economic policies. En J. Ravenhill (Ed.), Global political economy revised (pp. 51-83). Oxford University Press.

Keck, M., \& Sikkink, K. (1998). Activist beyond borders: Advocacy networks in international politics. Ithaca, NY: Cornell University Press.

Keohane, R. (1990). El concepto de interdependencia y el análisis de las relaciones asimétricas. En B. Torres (Ed.), Interdependencia: ¿Un enfoque útil para análisis de las relaciones México-Estados Unidos? (pp. 63-87). México DF: Colegio de México.

Krasner, S. (1990). Interdependencia simple y obstáculos para la cooperación entre México y Estados Unidos. En B. Torres (Ed.), Interdependencia: ¿Un enfoque útil para análisis de las relaciones México-Estados Unidos? (pp. 45-63). México DF: Colegio de México.

Lax, D. A., \& Sebenius, J. K. (1986). The power of alternatives or the limits of negotiation. Negotiation Journal, 1, 163-179.

Lax, D. A., Sebenius, J. K., Weber, R., Samuelson, W., \& Weeks, T. (1985). The manager as negotiator and dispute resolver. NIDR teaching materials series. Washington, D.C.: National Institute for Dispute Resolution.

Leal Buitrago, F. (2006). La inseguridad de la seguridad: Colombia, 1958-2005. Bogotá: Editorial Planeta.

Leiteritz, R. (2006). International political economy: The state of the art. Colombia Internacional, 1(62), 3-20.

Levitsky, S., \& Burgess K. (2003). Explaining populist party adaptation in Latin America: Environmental and organizational determinants of party change in Argentina, Mexico, Peru, and Venezuela. Comparative Political Studies, 36(8), 881-911.

Levitsky, S., \& Way, L. (1998). Between a shock and a hard place: The dynamics of labor-backed adjustments in Poland and Argentina. Comparative Politics, 30(2), 171-192.

Maher, K. (9 de enero de 2009). AFL-CIO, breakaway unions discuss reuniting. Wall Street Journal.

Moravcsik. (1993). Integrating international and domestic theories of international bargaining. En P. Evans, H. Jacobson \& R. Putnam (Eds.), Double-edged diplomacy: Interactive games in international affairs. Berkeley: University of California Press. 
Murillo, M. V., \& Schrank, A. (2005). With a little help from my friends: Partisan politics, transnational alliances and labor rights in Latin America. Comparative Political Studies, (8), 971-999.

Office of the United States Trade Representative - Bipartisan Agreement on Trade Policy. (mayo de 2007). Recuperado de https:/ / ustr.gov/ sites / default/files/uploads/factsheets/2007/asset_upload_file127_11319. pdf

Pizarro, R. (2006). The free trade agreement between the USA and Chile: An instrument of us commercial interests. The Ideas Working Paper Series (2), 1-34.

Public Citizen. (18 de septiembre de 2007). Change to win unions oppose peru NAFTA expansion. Recuperado de http:/ / citizen.typepad.com/ eyesontrade/2007/09/change-to-win-u.html

Pulecio, J. R. (2005). La estrategia Uribe de negociación del TLC. Colombia Internacional (61), 13-32.

Putnam, R. (1993). Diplomacy and domestic politics: The logic of twolevel games. En E. Jacobs \& R. Putnam (Ed.), Double-edged diplomacy: International bargaining and domestic politics (pp. 431-468). Berkely: University of California Press.

Rettberg, A., De Lombaerde, P., Lizarazo-Rodríguez, L., \& Ortiz-Riomalo, J. (2014). Rights, free trade, and politics: The strategic use of a rights discourse in the negotiation of free trade agreements (FTAs). Colombia Internacional (81), 129-165.

Roberts, K. (2002). Social inequalities without class cleavages in Latin America's neoliberal era. Studies in Comparative International Development, 36(4), 3-33.

Rodríguez, C., \& Rodríguez, D. (enero-marzo 2007). ¿Es constitucional el TLC? Derechos y Economía (1).

Semana. (21 de enero de 2011). Nota de prensa. Recuperado de http:/ / www. semana.com/nacion/articulo/vicepresidente-angelino-garzon-viajaraeeuu-para-impulsar-tlc-atpdea/234354-3

Semana. (12 de mayo de 2012). Nota de prensa. Recuperado de http:/ / www. semana.com/nacion/articulo/sindicatos-posibles-trabas-tlc/256285-3

Swanson, I. (19 de septiembre de 2007). Labor groups differ on Peru free trade deal. Recuperado de http:/ / www.bilaterals.org/?labor-groups-differon-peru-free\&lang $=$ en 
Silva, L. C. (2007). El proceso de negociación del TLC entre Colombia y Estados Unidos. Colombia Internacional, (65), 112-133.

Thaler, R. (1993). The Winner's Curse: Paradoxes and Anomalies of Economic Life. New York: Princeton University Press. Tarrow, S. (1998). Power in movement. Cambridge University Press.

Tickner, A., \& Morales, M. (2015). Narrating success: Colombian security expertise and foreign policy. En B. M. Bagley \& J. D. Rosen (Eds.), Colombia's political economy at the outset of the twenty-first century (241-259). Lanham, MD: Lexington Books.

Webber, J. (enero 2007). Empire's island in a sea of struggle. International viewpoint: News and analysis from the fourth international. Recuperado de http:/ / internationalviewpoint.org/spip.php?article1198 